\title{
The Role of Complementary and Alternative Medicine (CAM) in Rheumatology - It's Time for Integrative Medicine
}

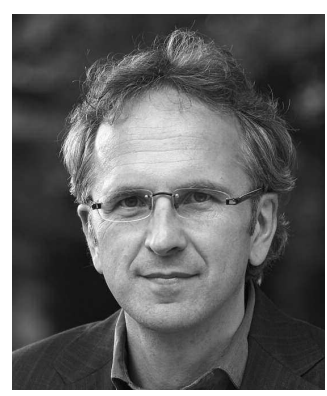

Complementary and alternative medicine (CAM) is defined by the National Center for Complementary and Alternative Medicine of the US National Institutes of Health as a group of various, mostly traditional or lifestyle-based medical treatments. CAM is classified in 5 groups: (1) Biology-based therapies such as diet, natural product supplements, and herbal therapy; (2) manipulative and body-based practices; for example, massage, manual therapy, chiropractic, osteopathy, reflexology, and movement therapies, such as the Feldenkrais method or Alexander technique; (3) mind-body interventions, such as meditation, yoga, relaxation therapy, breathing techniques, biofeedback, and hypnosis; (4) energy therapies, such as therapeutic touch, prayer, reiki, and qigong, and (5) whole medical systems, such as traditional Chinese medicine, traditional Indian medicine (Ayurveda, Siddha) as well as anthroposophical medicine, naturopathy, and homeopathy.

Of note, in Germany and central Europe, naturopathy has been established as a mainstream medicine for many decades; and includes exercise, nutrition and diet, hydrotherapy, balneotherapy, and other techniques of physical therapy.

The usage and popularity of CAM have steadily increased throughout the world. CAM use is especially high in patients with chronic diseases, and musculoskeletal conditions are by far the most common reason for using such treatments ${ }^{1}$. The use of CAM is not only motivated by dissatisfaction with conventional medicine but supported by individual belief systems, their perception of being safe and "soft," and their holistic approach. Moreover, many patients with chronic pain and rheumatic disease suffer from adverse effects of pain killers and nonsteroidal antiinflammatory drugs, which are also associated with substantial morbidity and mortality. Other patients wish to avoid or postpone invasive and surgical interventions.

Bearing in mind that third-party research funds for CAM are scarce and research structures cannot be compared to conventional disciplines, a remarkable body of evidence has been accumulated in recent years. Clearly, there is a further extensive need for scientific evaluation of CAM and for prioritizing the research topics. However, as in other fields of nonpharmacologic treatment, such as physical therapy, psychotherapy, balneology, and rehabilitation, the limited access to research funding will result in a slow increase of evidence. In the meantime, it should be remembered that the absence of evidence is not the evidence of absence of efficacy for a given method.

Based on currently available data, the most effective and promising methods in rheumatic disease and chronic pain can be summarized as follows.

\section{RHEUMATOID ARTHRITIS}

Borage seed oil and thunder god vine (Trypterigium wilfordii hook), oils containing gamma linolenic acid, are 2 compounds that have shown promising evidence for rheumatoid arthritis (RA) ${ }^{2}$. Moreover, a recent pilot trial on traditional Indian medicine found comparable effects of individualized ayurvedic medicine and methotrexate ${ }^{3}$. There is controversy about the role of nutrition in rheumatology. The Mediterranean diet has been found to be effective in RA. Further, it is well established as a very effective secondary prevention in coronary disease ${ }^{4}$. Because RA is associated with increased mortality due to cardiovascular disease, this underlines the therapeutic potential of a plant-based Mediterranean diet in the management of patients with RA. Recent experimental research points further to the potential of caloric restriction in inflammatory, degenerative, and metabolic disease ${ }^{5}$. Available evidence suggests that periods of 7 to 10 days of modified fasting followed by restricted diet might be useful in the treatment of $\mathrm{RA}^{6,7}$. Within the experience of our tertiary center for rheumatic disease, fasting cures have been performed in thousands of patients with reliable symptom relief and patient satisfaction. More randomized longterm studies are needed to confirm this view based on convincing data.

See C'mon CAM, page 544

Personal non-commercial use only. The Journal of Rheumatology Copyright @ 2013 . All rights reserved. 


\section{OSTEOARTHRITIS}

Several methods of CAM and naturopathy have been found effective in the treatment of osteoarthritis (OA), among them hydrotherapy, balneotherapy, thermal therapy, and specific movement therapies, such as tai chi. However, there is a lack of evidence for most herbal treatments, and only moderate effects are found for the most popular compounds such as rose hip (Rosa canina), devil's claw (Harpagophytum procumbens), or willow bark extract (Salicis cortex). Also, most supplements and local injection therapies produced negative results in controlled trials and cannot be recommended. To the contrary, some traditional treatments are effective in the symptomatic treatment of OA. Traditional leech therapy is being used once again for the treatment of OA, a recent systematic review on leech therapy found moderate to strong evidence for the reduction of pain, functional impairment, and joint stiffness in patients with OA of the $\mathrm{knee}^{8}$. Symptomatic improvement has also been described for rhizarthrosis ${ }^{9}$. Acupuncture has been extensively studied for OA and chronic pain conditions. In the largest metaanalysis performed so far, acupuncture was superior to both sham and no-acupuncture control for each pain condition including $\mathrm{OA}^{10}$. Of note, the effect of acupuncture can be maximized through a patient-practitioner relationship augmented by warmth, attention, and confidence ${ }^{11}$.

\section{CHRONIC BACK AND NECK PAIN}

Various mind-body and movement therapies of CAM have been investigated in the treatment of nonspecific chronic low back and neck pain, with yoga and Alexander technique appearing as the most effective methods ${ }^{12,13}$. A favorable aspect of most complementary movement therapies consists of their frequent combination of muscle strengthening, stretching, and relaxation response. Beneficial aspects of yoga also include improvements in quality of life, stress reduction, and psychological well-being ${ }^{14}$. Since yoga can be implemented easily as a self-care method its cost-effectiveness seems promising, and patients with chronic pain conditions should be encouraged to practice yoga. Acupuncture is a very popular treatment for chronic back pain. Although acupuncture was found effective in several trials, the main purported mechanisms remain unclear. Other treatment methods of traditional Asian medicine, such as cupping, gua sha, or reflex massages are increasingly used in CAM and found to be effective in preliminary trials. Interestingly, repetitive treatment with a nonspecific nociceptive stimulus, such as a needle pad, also reduces pain and concomitantly increases pressure pain thresholds ${ }^{15}$. Further neurophysiological mechanisms possibly related to the pain-relieving effect of these reflex treatments have been described and include the stimulation of multireceptive dorsal horn neurons and diffuse noxious inhibitory controls ${ }^{16}$.
A variety of manual and chiropractic techniques, as well as massage techniques, are frequently applied in the management of chronic back and neck pain. These interventions mostly improve pain in the short and medium term. However, the effects are mostly not very clinically meaningful. Manipulation should preferably be used in conjunction with exercise to improve outcomes and to avoid a decrease in patients' self-efficacy.

\section{FIBROMYALGIA}

Fibromyalgia (FM) as a complex disorder poses limitations in treatment success for both conventional and complementary medicine. Nonpharmacological approaches, such as exercise and education, are strongly recommended, but incorporation into patient care is unsatisfying. For most practitioner-based complementary therapies, such as acupuncture or manual therapy, analgesic effects are only small and non-lasting. Therefore, these treatments cannot be recommended for the management of FM. In contrast, recent research testing mind-body and meditative movement interventions has found considerable benefits, especially for tai chi, in patients with $\mathrm{FM}^{17,18}$. Further useful treatments are hydrotherapy and thermal therapy ${ }^{19}$. The majority of patients with FM feel symptom relief when applying local heat. Systemic whole-body hyperthermia can produce additional benefits when applied as an adjunct to a standard multimodal treatment ${ }^{20}$. Elimination diets and fasting are frequently reported as being beneficial for symptom relief by patients; however, so far there are no convincing data from controlled trials on diet and FM.

What might stand in the way of implementation of CAM in rheumatology? The potential of interactions or the danger of delayed conventional treatment can be minimized by treating the patient within an integrative setting with full transparency for all treating physicians. It is also argued that there is no need for CAM as all scientifically proven methods will be adopted by conventional medicine. Against this stands the fact that many fields of CAM need specific education, experience, and knowledge, and specialists will be necessary to ensure quality. Further, CAM methods are often blamed for being basically dependent on nonspecific or placebo-like effects. However, the complexity of nonspecific effects applies to both CAM and conventional medicine. Whereas some criticize CAM for relying too much on effectiveness instead of efficacy, one can in turn argue that conventional medicine should learn from CAM and try to maximize any nonspecific effects; as for the patient, only effectiveness and safety, but not efficacy, count. Finally, within the broad field of CAM, patients might be sold non-serious or too many CAM treatments. This type of malpractice can be best avoided by better integrating CAM into academic medicine and initiating stricter education and regulation.

Personal non-commercial use only. The Journal of Rheumatology Copyright @ 
CAM and naturopathy have arrived in evidence-based medicine. For care of patients with rheumatic disease and chronic pain, these could clearly be of benefit if CAM practitioners were more critical, and conventional practitioners were more open to applying an integrative medicine that uses all effective treatments available in 21 st-century medicine.

\author{
ANDREAS MICHALSEN, MD, \\ Professor of Medicine, \\ Charité University Medical Centre, \\ Institute of Social Medicine, Epidemiology, and Health Economics; \\ Director, Department of Internal and Integrative Medicine, \\ Immanuel Krankenhaus Berlin (Standort Berlin-Wannsee), \\ Königstraße 63, Berlin-Wannsee, Berlin 14109, Germany. \\ E-mail: A.Michalsen@immanuel.de
}

\section{REFERENCES}

1. Hunt KJ, Coelho HF, Wider B, Perry R, Hung SK, Terry R, et al. Complementary and alternative medicine use in England: results from a national survey. Int J Clin Practice 2010;64:1496-502.

2. Macfarlane GJ, Paudyal P, Doherty M, Ernst E, Lewith G, MacPherson $\mathrm{H}$, et al. A systematic review of evidence for the effectiveness of practitioner-based complementary and alternative therapies in the management of rheumatic diseases: rheumatoid arthritis. Rheumatology 2012;51:1707-13.

3. Furst DE, Venkatraman MM, McGann M, Manohar PR, Booth-LaForce C, Sarin R, et al. Double-blind, randomized, controlled, pilot study comparing classic ayurvedic medicine, methotrexate, and their combination in rheumatoid arthritis. J Clin Rheumatol 2011;17:185-92.

4. Skoldstam L, Hagfors L, Johansson G. An experimental study of a Mediterranean diet intervention for patients with rheumatoid arthritis. Ann Rheum Dis 2003;62:208-14.

5. Fontana L, Partridge L, Longo VD. Extending healthy life spanfrom yeast to humans. Science 2010;328:321-6.

6. Kjeldsen-Kragh J, Haugen M, Borchgrevink CF, Laerum E, Eek M, Mowinkel P, et al. Controlled trial of fasting and one-year vegetarian diet in rheumatoid arthritis. Lancet 1991;338:899-902.

7. Müller H, Wilhelmi de Toledo F, Resch KL. A systematic review of clinical studies on fasting and vegetarian diets in the treatment of rheumatoid arthritis. Scand J Rheumatol 2000;30:1-10.

8. Lauche R, Cramer H, Langhorst J, Dobos G. A systematic review and meta-analysis of medical leech therapy for osteoarthritis of the knee. Clin J Pain 2013:in press.
9. Michalsen A, Ludtke R, Cesur O, Afra D, Musial F, Baecker M, et al. Effectiveness of leech therapy in women with symptomatic arthrosis of the first carpometacarpal joint: a randomized controlled trial. Pain 2008; 137:452-9.

10. Vickers AJ, Cronin AM, Maschino AC, Lewith G, MacPherson H, Foster NE, et al. Acupuncture for chronic pain: individual patient data meta-analysis. Arch Intern Med 2012;172:1444-53.

11. Kaptchuk TJ, Kelley JM, Conboy LA, Davis RB, Kerr CE, Jacobson EE, et al. Components of placebo effect: randomised controlled trial in patients with irritable bowel syndrome. BMJ 2008;336:999-1003.

12. Bussing A, Ostermann T, Ludtke R, Michalsen A. Effects of yoga interventions on pain and pain-associated disability: a meta-analysis. J Pain 2012;13:1-9.

13. Little P, Lewith G, Webley F, Evans M, Beattie A, Middleton K, et al. Randomised controlled trial of Alexander technique lessons, exercise, and massage (ATEAM) for chronic and recurrent back pain. BMJ 2008;337:a884.

14. Michalsen A, Traitteur H, Ludtke R, Brunnhuber S, Meier L, Jeitler $\mathrm{M}$, et al. Yoga for chronic neck pain: a pilot randomized controlled clinical trial. J Pain 2012;13:1122-30.

15. Lauche R, Cramer H, Hohmann C, Choi KE, Rampp T, Saha FJ, et al. The effect of traditional cupping on pain and mechanical thresholds in patients with chronic nonspecific neck pain: a randomised controlled pilot study. Evid Based Complement Alternat Med 2012;2012:429718.

16. Musial F, Michalsen A, Dobos G. Functional chronic pain syndromes and naturopathic treatments: neurobiological foundations. Forsch Komplementmed 2008;15:97-103.

17. Langhorst J, Klose P, Dobos GJ, Bernardy K, Hauser W. Efficacy and safety of meditative movement therapies in fibromyalgia syndrome: a systematic review and meta-analysis of randomized controlled trials. Rheumatol Int 2013;33:193-207.

18. Wang C, Schmid CH, Rones R, Kalish R, Yinh J, Goldenberg DL, et al. A randomized trial of tai chi for fibromyalgia. New Engl J Med 2010;363:743-54.

19. Langhorst J, Musial F, Klose P, Hauser W. Efficacy of hydrotherapy in fibromyalgia syndrome - a meta-analysis of randomized controlled clinical trials. Rheumatology 2009;48:1155-9.

20. Brockow T, Wagner A, Franke A, Offenbacher M, Resch KL. A randomized controlled trial on the effectiveness of mild water-filtered near infrared whole-body hyperthermia as an adjunct to a standard multimodal rehabilitation in the treatment of fibromyalgia. Clin J Pain 2007;23:67-75.

J Rheumatol 2013;40:547-9; doi:10.3899/jrheum.130107 